\title{
MEASUREMENT OF SPECIFIC FRACTURE ENERGY AND SURFACE TENSION OF BRITTLE MATERIALS IN POWDER FORM
}

\author{
Petr Jandacka ${ }^{1}$, Libor M Hlavac ${ }^{1}$, Vilem Madr ${ }^{1}$, Jindrich Sancer ${ }^{2}$, Frantisek Stanek ${ }^{1}$ \\ ${ }^{1}$ Institute of Physics, ${ }^{2}$ Institute of Mining Engineering and Safety, Technical University of Ostrava, \\ 17. listopadu 15/2172,70800 Ostrava, Czech Republic \\ e-mail:petr.jandacka@vsb.cz
}

\begin{abstract}
This article presents a method for the experimental measurement of specific fracture energy and surface tension of a brittle materials in a powder form. This work is focused on testing a method on the mineral, almandine. A hydraulic press was used in the experiment to crush powder particles, and statistical evaluation was used to analyze the change in the powder surface. The powder was subject to various conditions during crushing. The crushing was performed both in air and in water. It was done at three different compression speeds, namely $15.8 \mathrm{MPa} / \mathrm{s}, 3.95 \mathrm{MPa} / \mathrm{s}$ and $2.25 \mathrm{MPa} / \mathrm{s}$. The experimental results showed measurable differences in the specific fracture energy values in the presented regimes.
\end{abstract}

\section{Keywords: specific fracture energy, crushing, fragmentation, specific surface, powder}

1. Introduction. Theoretical calculations and experimental measurements of specific fracture energy are very difficult. Calculations are possible for expressing of surface tension and simpler bonds with a pronounced type of structure, like $\mathrm{NaCl}, \mathrm{MgO}$ with ionic bonds and $\mathrm{Si}$ with a covalent bond, see the below mentioned references. During experimental measurement of the specific fracture energy, the analysis of the work needed to create the new surface and analysis of the size of a newly created surface are necessary. The analysis of the surface size difference is especially problematic due to the complexity of the shape of the newly created surface. The best methods for evaluation of powder surface size, seems to be BET method for analyzing the adsorption of gas on a powder surface as is presented by Brantley and Mellott (2000).

The substitution of powder particles with smooth spheres is the first appropriate approximation for a tested material in a powder form. So only the geometrical powder surface is evaluated (Brantley and Mellott (2000)). Such a simplification was used in this article.

From the application point of view, hard powder materials can be used as abrasives, for example in high-speed abrasive water jets. The specific surface energy value or the specific fracture energy value is used in expressions describing the abrasive processes (Hlavac et al. (2007)) or comminution processes (Hlavac et al. (2009)).

The analyses of a specific surface (fracture) energy of solid matter were done semi-empirically by Keller (1954), Tromans and Meech (2002), Woensdregt (1992), and experimentally by Gilman (1960), Messmer and Bilello (1981), Davidge and Tappin (1968), Friedman et al. (1972). These experimental methods are usually based on the fracture or cleavage of crystals. Generally the fragmentation processes were analyzed by Miller et al. (1999), Pitchumani et al. (2004) or Pugno and Carpinteri (2008). This article focuses on the measurement of fracture energy of powder almandine in six regimes of fragmentation, using a hydraulic press. 
2. Specific Fracture Energy of Brittle Materials. Integration of the first thermodynamic law with the Gibbs-Duhem equation as in Adamson (1990), Bechstedt (2003), Lüth (2001), when no other heat exchange subsists between the system and its surroundings (adiabatic process), leads to the expression for mechanical work $W_{\text {mech }}$ performed on material through equations eqs. (1a) and (1b)

$$
\begin{gathered}
\mathrm{d} W_{\text {mech }}=\mathrm{d} U=\mathrm{d} H=\mathrm{d} W^{V}+\mathrm{d} W^{A} \\
\mathrm{~d} W_{\text {mech }}=\left(\mathrm{d} W_{\mathrm{el}}^{V}+\mathrm{d} W_{\mathrm{pl}}^{V}\right)+\left(\mathrm{d} W_{\mathrm{el}}^{A}+\mathrm{d} W_{\mathrm{pl}}^{A}+\sum_{i=1}^{n} \mu_{i} \mathrm{~d} n_{i}\right)
\end{gathered}
$$

where $U$ is the internal energy, $H$ is the enthalpy, $W^{V}$ is the volume work, $W^{A}$ is the surface work, the lower indexes "el" and "pl" distinguish the elastic and plastic components of these values respectively, $\mu_{i}$ is a chemical potential and $n_{i}$ is the number of adsorbed particles of the $i$-th component being in contact with the powder surface.

If at least one of the system components is in the condensed state, the relation $\mathrm{d} U=\mathrm{d} H$ is valid, and the following expression for the specific fracture energy of brittle material can be written as

$$
\sigma_{\text {fract }}=\frac{\partial W^{A}}{\partial A}
$$

where $A$ is the area change. A surface tension (free specific surface energy), or more correctly interfacial tension (Adamson (1990)), is determined by the equation

$$
\gamma=\frac{\partial\left(W^{A}-W_{\mathrm{pl}}^{A}\right)}{\partial A}
$$

The surface plastic work $W_{\mathrm{pl}}^{A}$ is connected to the plastic deformation of a surface layer, in agreement with the generally accepted finding of fracture mechanics that the fracture of brittle material is accompanied by a slight area of plastic deformation surrounding the propagating fracture front. This presumption has been proven by X-ray methods (Tkacova (1989)).

In the case of solid matter the specific fracture energy $\sigma_{\text {fract }}$ is an anisotropic value and depends on the direction of separate crystallographic planes $\{h k l\}$, as presented by Tromans and Meech (2002). The effective values of $\sigma_{\text {fract }}$ have been analyzed within the below mentioned experimental measurement. The specific fracture energy value also depends on other quantities, like thermodynamic temperature $T$, or particle size $d_{i}$.

3. Experimental Set-up and Progress of Measurements. The experimental procedure was as follows: Approximately $30 \mathrm{~g}$ of the mineral almandine was poured into the crusher schematically shown in Fig 1. It is assumed that these are mostly monocrystallic particles (considering their size). This material was then crushed in the crusher by a high-precision hydraulic press. The work needed for crushing can be calculated from the records of the press movement and the exerted force. A change in the powder particle surface was evaluated by statistical analysis, using a laser analyser. The software of the laser analyser puts out values of fractiles for particle sizes $d_{0.5}$ and $d_{0.9}$, and these values were used for calculation of the specific surfaces.

The crusher (Fig. 1) was made by reseach team. It consists of steel and corundum. The corundum prevents friction of particles on the steel walls of the cylinder. The crusher casing diameter is $60 \mathrm{~mm}$ and its height is $60 \mathrm{~mm}$ as well. The piston and the inner part of the corundum calix diameters are 25 $\mathrm{mm}$. Piston walls and the corundum calix do not fit closely together, therefore the fluid that 
surrounds the powder can flow out freely during compression. A hole was drilled into the crusher from the side, in order to measure the temperature of the powder. Such a crusher can work reliably up to the force of $60 \mathrm{kN}$. At this point, the corundum circle starts to break.

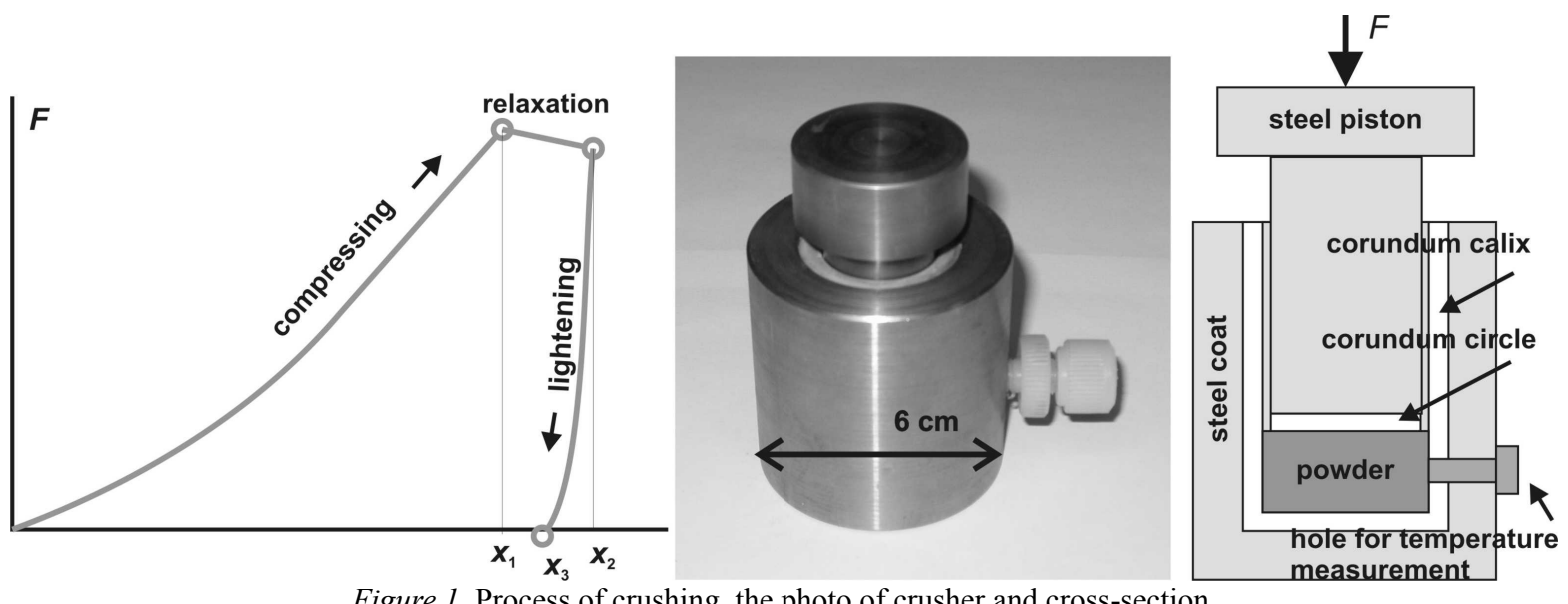

Figure 1. Process of crushing, the photo of crusher and cross-section.

In general the crushing consists of three phases (see Fig. 1). The first phase, the compression, is determined by the compression force $F_{\text {comp }}$ and the compression work $W_{\text {comp }}$

$$
W_{\text {comp }}=\int_{0}^{x_{1}} F_{\text {comp }} \mathrm{d} x
$$

where $\mathrm{d} x$ is the differential movement of the press.

The second phase, the relaxation, starts when the hydraulic press is stopped and a part of the potential energy collected in the experimental system is released in order to create new powder surfaces

$$
W_{\text {relax }}=\int_{x_{1}}^{x_{2}} F_{\text {relax }} \mathrm{d} x
$$

The third phase, the lightening, points out to the potential energy of elasticity of the compressed system (powder and crusher), which is returned to the press during lightening

$$
W_{\text {light }}=-\int_{x_{2}}^{x_{3}} F_{\text {light }} \mathrm{d} x
$$

The crushing work is then

$$
W_{\text {crush }}=W_{\text {comp }}+W_{\text {relax }}-W_{\text {light }}
$$

In the case of the presented experimental measurement the compression periods were 5, 20 and $35 \mathrm{~s}$, relaxation periods were about $10 \mathrm{~s}$ for all samples, and the lightening periods were almost the same as the compressions. The mentioned works were computed by smoothing the experimental points using the polynomial function.

Eighteen compressions were performed in total. The compressions were always performed three times in the same regime and in the same component (water or air) for increased pressure speeds of 
$15.8 \mathrm{MPa} / \mathrm{s}, 3.95 \mathrm{MPa} / \mathrm{s}$ and $2.25 \mathrm{MPa} / \mathrm{s}$. The final pressure of the press was always $79 \mathrm{MPa}(40 \mathrm{kN})$. The maximum movement of the crusher piston was approximately $5 \mathrm{~mm}$. The value of the pressure force and movement of the press were recorded by a computer with the frequency of 10 points per second $(10 \mathrm{~Hz})$ during crushing. Table 1 shows partial values of work of all samples.

\begin{tabular}{rcccccc}
\multicolumn{7}{c}{ Table 1. Partial values of crushing work. } \\
\hline $\begin{aligned} \text { Sample } \\
\text { number }\end{aligned}$ & Mode & $\begin{array}{c}\text { Contact } \\
\text { compon. }\end{array}$ & $\begin{array}{c}W_{\text {comp }} \\
(\mathrm{J})\end{array}$ & $\begin{array}{c}W_{\text {relax }} \\
(\mathrm{J})\end{array}$ & $\begin{array}{c}W_{\text {ligth }} \\
(\mathrm{J})\end{array}$ & $\begin{array}{c}W_{\text {crush }} \\
(\mathrm{J})\end{array}$ \\
\hline 1 & $15.8 \mathrm{MPa} / \mathrm{s}$ & air & 77.23 & 17.17 & 4.22 & 90.18 \\
2 & $15.8 \mathrm{MPa} / \mathrm{s}$ & air & 72.60 & 17.15 & 4.92 & 84.83 \\
3 & $15.8 \mathrm{MPa} / \mathrm{s}$ & air & 69.38 & 16.22 & 2.20 & 83.40 \\
4 & $15.8 \mathrm{MPa} / \mathrm{s}$ & water & 74.53 & 13.23 & 3.23 & 84.53 \\
5 & $15.8 \mathrm{MPa} / \mathrm{s}$ & water & 79.50 & 10.51 & 6.01 & 84.00 \\
6 & $15.8 \mathrm{MPa} / \mathrm{s}$ & water & 80.64 & 11.75 & 6.58 & 85.81 \\
7 & $3.95 \mathrm{MPa} / \mathrm{s}$ & air & 75.47 & 11.83 & 1.92 & 85.37 \\
8 & $3.95 \mathrm{MPa} / \mathrm{s}$ & air & 80.36 & 11.64 & 4.28 & 87.72 \\
9 & $3.95 \mathrm{MPa} / \mathrm{s}$ & air & 78.42 & 10.36 & 5.66 & 83.12 \\
10 & $3.95 \mathrm{MPa} / \mathrm{s}$ & water & 72.01 & 9.71 & 2.04 & 79.69 \\
11 & $3.95 \mathrm{MPa} / \mathrm{s}$ & water & 77.67 & 9.50 & 3.04 & 84.12 \\
12 & $3.95 \mathrm{MPa} / \mathrm{s}$ & water & 75.94 & 10.69 & 3.13 & 83.49 \\
13 & $2.25 \mathrm{MPa} / \mathrm{s}$ & air & 78.73 & 6.32 & 3.53 & 81.52 \\
14 & $2.25 \mathrm{MPa} / \mathrm{s}$ & air & 79.36 & 6.60 & 2.54 & 83.42 \\
15 & $2.25 \mathrm{MPa} / \mathrm{s}$ & air & 77.29 & 8.73 & 4.16 & 81.86 \\
16 & $2.25 \mathrm{MPa} / \mathrm{s}$ & water & 76.28 & 4.77 & 0.18 & 80.87 \\
17 & $2.25 \mathrm{MPa} / \mathrm{s}$ & water & 79.41 & 6.55 & 3.61 & 82.35 \\
18 & $2.25 \mathrm{MPa} / \mathrm{s}$ & water & 81.24 & 6.33 & 3.50 & 84.07 \\
\hline
\end{tabular}

4. Computational Relations. The size of almandine particles before crushing was (100-800) $\mu \mathrm{m}$ and after crushing it was approximately $1 \mu \mathrm{m}$ (the finest $400 \mathrm{~nm}$ ), as it is documented in Fig. 2.

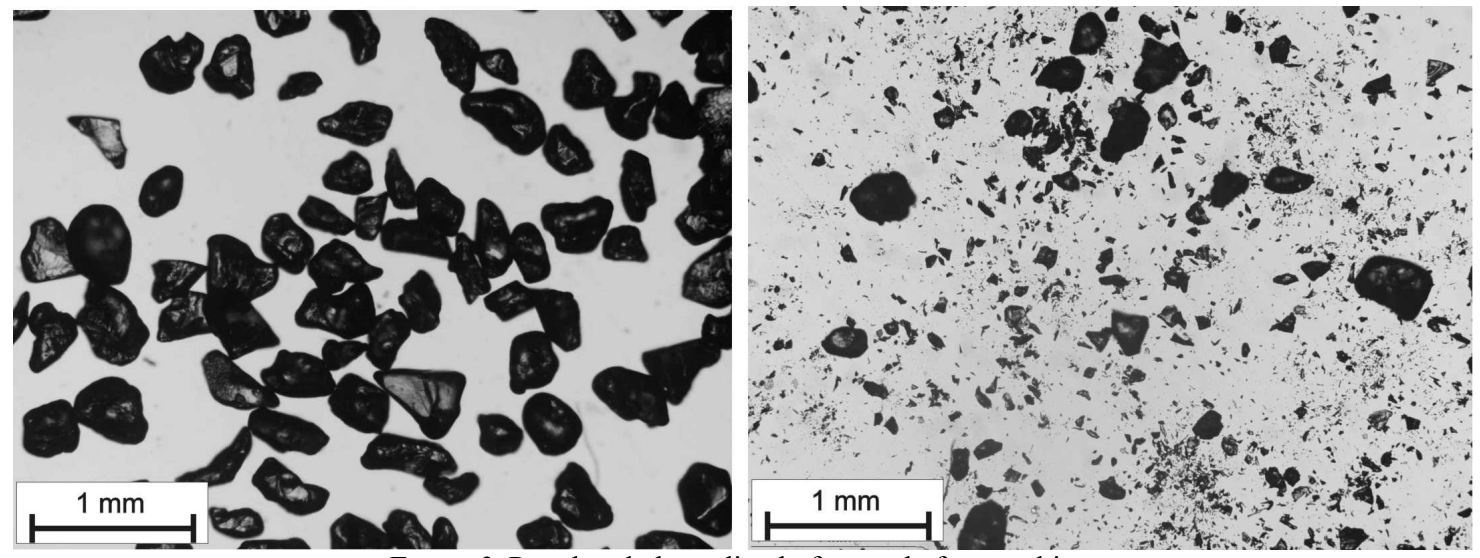

Figure 2. Powdered almandine before and after crushing.

Measurement of the size of the specific geometry surface of powder $A_{\text {geo }}$ was based on the measurement of particle sizes using a laser analyser. Considering the assumption of logarithmicnormal distribution of the particle sizes, as presented by Likes and Machek (1987) and Brantley and Mellot (2000), it is possible to calculate specific geometry surface, using the expression

$$
A_{\text {geo }}=\frac{6}{\rho \exp \left(\mu+2.5 \omega^{2}\right)}
$$


where $\rho$ is the powder density, $\mu$ is the arithmetic mean of logarithms of particle sizes $\ln \left(d_{i}\right)$ and $\omega^{2}$ is the dispersion of values $\ln \left(d_{i}\right)$ (Jandacka and Hlavac (2007)). Values $\mu$ and $\omega^{2}$ can be determined from the two parameters found by granulometric analysis, applying the findings of the normal (Gauss) distribution. The experimental output, the $d_{0.5}$ (median) and $d_{0.9}$ (90 percent fractile), were used for calculation of $\mu=\ln \left(d_{0.5}\right)$ and $\omega=\left(\ln d_{0.9}-\mu\right) / 1.29 .1 .29$ is the value that corresponds to the standard value of the distribution function $F(0.9)$ of the normal distribution. Instead the eq. (8) the expression $A_{\mathrm{geo}}=6 /(\rho d)$ is often used, for example in Papelis et al. (2003), Hunger and Brouvers (2009), Masteau and Thomas (1999), Parfitt and Sing (1986), where $d$ is the arithmetic mean.

The specific fracture energy can be then calculated in agreement with eq. (2) as

$$
\sigma_{\text {fract }}=\frac{W_{\text {crush }}}{m \cdot \Delta A_{\text {geo }}}
$$

where $m$ is the weight of the powder and $\Delta A_{\text {geo }}$ is the difference in size of the specific geometric surface before and after crushing. Surface tension, in agreement with eq. (3), is then calculated as

$$
\gamma=\frac{W_{\text {crush }}-m c \Delta T}{m \cdot \Delta A_{\text {geo }}}
$$

where $c$ is the specific heat capacity of the powder and $\Delta T$ is the powder temperature change during the crushing process. The powder temperature change is connected to plastic deformations of the powder particles, mainly in the surface layer.

5. Experimental Results. Non-porous almandine powder was used for the measurements. This is an abrasive mineral with the hardness 8.5 on the Mohs scale, with a mineralogical purity of $97 \%$, chemical composition $\mathrm{Fe}_{3} \mathrm{Al}_{2} \mathrm{Si}_{3} \mathrm{O}_{12}$, and a specific heat capacity $720 \mathrm{Jkg}^{-1} \mathrm{~K}^{-1}$, density $4084 \mathrm{~kg} \cdot \mathrm{m}^{-3}$.

\begin{tabular}{|c|c|c|c|c|c|c|c|c|c|c|c|c|}
\hline $\begin{array}{l}\text { Sample } \\
\text { number }\end{array}$ & Mode & $\begin{array}{l}\text { Contact } \\
\text { compon. }\end{array}$ & $\begin{array}{l}d_{0.5} \\
\text { after } \\
(\mu \mathrm{m})\end{array}$ & $\begin{array}{l}d_{0.9} \\
\text { after } \\
(\mu \mathrm{m})\end{array}$ & $\begin{array}{c}A_{\text {geo }} \\
\text { after } \\
\left(\mathrm{m}^{2} \mathrm{~g}^{-1}\right)\end{array}$ & $\begin{array}{c}A_{\text {geo }} \\
\text { before } \\
\left(\mathrm{m}^{2} \mathrm{~g}^{-1}\right)\end{array}$ & $\begin{array}{l}\Delta A_{\text {geo }} \\
\left(\mathrm{m}^{2} \mathrm{~g}^{-1}\right)\end{array}$ & $\begin{array}{l}m \\
(\mathrm{~g})\end{array}$ & $\begin{array}{c}W_{\text {crush }} \\
\text { (J) }\end{array}$ & $\begin{array}{l}\sigma_{\text {fract }} \\
\left(\mathrm{Jm}^{-2}\right)\end{array}$ & $\begin{array}{l}\Delta T \\
(\mathrm{~K})\end{array}$ & $\begin{array}{c}\gamma \\
\left(\mathrm{Jm}^{-2}\right)\end{array}$ \\
\hline 1 & $15.8 \mathrm{MPa} / \mathrm{s}$ & air & 0.75 & 1.41 & 1.07 & 0.0046 & 1.07 & 28.77 & 90.18 & 2.94 & 1.00 & 2.26 \\
\hline 2 & $15.8 \mathrm{MPa} / \mathrm{s}$ & air & 0.86 & 1.62 & 0.94 & 0.0046 & 0.93 & 28.49 & 84.83 & 3.19 & 0.60 & 2.73 \\
\hline 3 & $15.8 \mathrm{MPa} / \mathrm{s}$ & air & 1.00 & 1.89 & 0.80 & 0.0046 & 0.80 & 28.44 & 83.40 & 3.69 & 0.70 & 3.05 \\
\hline 4 & $15.8 \mathrm{MPa} / \mathrm{s}$ & water & 0.75 & 1.43 & 1.06 & 0.0046 & 1.05 & 28.34 & 84.53 & 2.84 & - & - \\
\hline 5 & $15.8 \mathrm{MPa} / \mathrm{s}$ & water & 0.74 & 1.44 & 1.02 & 0.0046 & 1.02 & 28.50 & 84.00 & 2.90 & - & - \\
\hline 6 & $15.8 \mathrm{MPa} / \mathrm{s}$ & water & 0.75 & 1.42 & 1.06 & 0.0046 & 1.05 & 28.59 & 85.81 & 2.85 & - & - \\
\hline 7 & $3.95 \mathrm{MPa} / \mathrm{s}$ & air & 0.75 & 1.42 & 1.07 & 0.0046 & 1.06 & 28.04 & 85.37 & 2.86 & 0.40 & 2.59 \\
\hline 8 & $3.95 \mathrm{MPa} / \mathrm{s}$ & air & 0.75 & 1.40 & 1.09 & 0.0046 & 1.09 & 28.51 & 87.72 & 2.83 & 0.50 & 2.50 \\
\hline 9 & $3.95 \mathrm{MPa} / \mathrm{s}$ & air & 0.75 & 1.41 & 1.08 & 0.0046 & 1.08 & 28.14 & 83.12 & 2.74 & 0.60 & 2.34 \\
\hline 10 & $3.95 \mathrm{MPa} / \mathrm{s}$ & water & 0.66 & 1.23 & 1.24 & 0.0046 & 1.23 & 28.72 & 79.69 & 2.25 & - & - \\
\hline 11 & $3.95 \mathrm{MPa} / \mathrm{s}$ & water & 0.76 & 1.43 & 1.05 & 0.0046 & 1.05 & 28.75 & 84.12 & 2.80 & - & - \\
\hline 12 & $3.95 \mathrm{MPa} / \mathrm{s}$ & water & 0.75 & 1.43 & 1.05 & 0.0046 & 1.05 & 28.21 & 83.49 & 2.83 & - & - \\
\hline 13 & $2.25 \mathrm{MPa} / \mathrm{s}$ & air & 0.86 & 1.62 & 0.93 & 0.0046 & 0.93 & 28.41 & 81.52 & 3.09 & - & - \\
\hline 14 & $2.25 \mathrm{MPa} / \mathrm{s}$ & air & 0.78 & 1.46 & 1.05 & 0.0046 & 1.05 & 28.55 & 83.42 & 2.79 & - & - \\
\hline 15 & $2.25 \mathrm{MPa} / \mathrm{s}$ & air & 0.86 & 1.62 & 0.94 & 0.0046 & 0.93 & 28.48 & 81.86 & 3.08 & - & - \\
\hline 16 & $2.25 \mathrm{MPa} / \mathrm{s}$ & water & 0.75 & 1.41 & 1.07 & 0.0046 & 1.07 & 28.79 & 80.87 & 2.63 & - & - \\
\hline 17 & $2.25 \mathrm{MPa} / \mathrm{s}$ & water & 0.66 & 1.22 & 1.25 & 0.0046 & 1.25 & 28.56 & 82.35 & 2.31 & - & - \\
\hline 18 & $2.25 \mathrm{MPa} / \mathrm{s}$ & water & 0.66 & 1.24 & 1.23 & 0.0046 & 1.23 & 28.42 & 84.07 & 2.41 & - & - \\
\hline
\end{tabular}

Table 2. Measured data and calculated quantities.

The surface tension is smaller than the specific fracture energy, which is in agreement with eqs. (2) and (3). For the $15.8 \mathrm{MPa} / \mathrm{s}$ test using air, the average value of the surface tension is $\gamma=2.68 \mathrm{Jm}^{-2}$ being the $82 \%$ of the measured specific fracture energy, and for the $3.95 \mathrm{MPa} / \mathrm{s}$ regime in air the 
surface tension is $\gamma=2.48 \mathrm{Jm}^{-2}$, i.e. $88 \%$. The temperature change was measured using a thermocouple sensor for area measurements put into contact with the powder surface. The outflow of heat from the crusher was negligible. The powder temperature changes during measurements in water were not measurable due to presence of water.

Fig. 3. shows the average values of the specific fracture energy and respective relative uncertainties. The estimation of uncertainties of the average value of the fracture energy is based, due to the complexity of the process, on the calculation of the maximum standard deviation of the arithmetic mean. This is $7 \%$. The most commonly cited research, Gillman (1960), uncertainty $15 \%$ for its measurement (applying the same computation). The estimation of accuracy of the method can be made using the almandine surface energy value assigned from literature. Tromans and Meech (2002) calculated value of the for random trans-crystallic fractures in almandine $\gamma=3.55 \mathrm{Jm}^{-2}$. There is approximately a $30 \%$ difference in the results of the surface tension presented here. The values about $0.1-10 \mathrm{~J} / \mathrm{m}^{2}$ could be expected as presented by Gilman (1960). Nevertheless, this issue would need to be discussed in wider scope reseach.

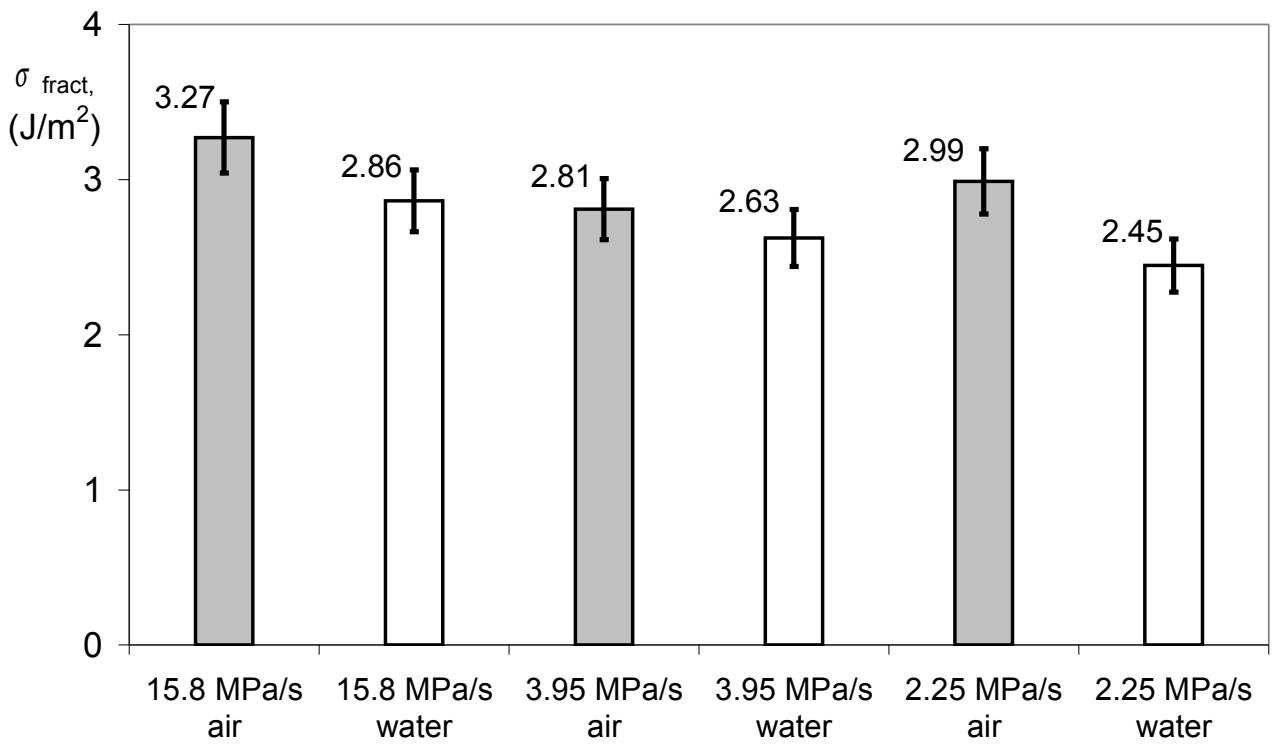

Figure 3. Average values of the specific fracture energy, uncertainty $7 \%$.

Results. The values of the specific fracture energy ranging from $2.5-3.3 \mathrm{~J} / \mathrm{m}^{2}$ in the measured regimes as is evident in Fig. 3. The value of the specific fracture energy increases in water with the speed of crushing, it is in agreement with the theoretical assumption about the amount $n_{i}$ of molecules of water adsorbed in front of an expanding fracture. The quantity should decrease with increasing crush-speed. It is possible to assume brittle fracture during very high speeds of crushing. It correlates with the values of $W_{\text {relax }}$ in Table 1 . This is in agreement with the theory of the behavior of dislocations. But in regime $15.8 \mathrm{MPa} / \mathrm{s}$ the specific fracture energy is higher than in regime 3.95 $\mathrm{MPa} / \mathrm{s}$. The conflict is induced by the relaxation phase (see Fig. 1). For determination of the exact reaction of the powder to the crushing speed the press must start the lightening, immediately stopping after compressing. The values of the specific fracture energy correlate with $\Delta A_{\text {geo }}$ as well (see Table 2).

Discussion of experimental conditions. There are measurable changes in the values of the specific 
fracture energy. This is physically very interesting from the point of view of the brittle materials. The change in crushing speed may create interesting differences in values, mainly for extreme cases as very high crushing speed and very low crushing speed. The working and temperature measurements make it possible to find the extent of the plastic deformation during the fracture.

The most commonly used experimental way of measuring the specific fracture energy of a solids is by breaking the crystals. But the size of the newly created surface is relatively small. The presented method has the advantage with relatively large newly created surfaces. This induces a measurable change in the temperature of the powder.

Friction. The change of the temperature of the brittle powder is induced by plastic zone on the new surface or friction of the particles one to another (or friction of the particles to the corundum). Since this is a brittle material, it can be assumed that while crushing the powder, the temperature change is not caused by the friction of powder particles. The mutual interaction caused by the movement of particles during crushing, or particles versus corundum, probably causes further breaking of the edges and tips. For example, the curundum calix remains undamaged inside after each of the measurements.

Future experimental activities. In furter experimental activities it is possible to focus on a larger set of powders, dependency on temperature and further regimes of crushing and contact components can be also studied. These results should be applicable to the processes of fragmentation of brittle materials as a comminution, crushing and abrasive processes under a wide scale of fragmentation speeds.

Smoothness of the particles. According to discussed accuracy the crushed particles are like smooth spheres. Which is advantageous for calculations.

6. Conclusions. The values of the specific fracture energy results in measurable changes according to crush-speed regime. When water is used as a component of the system, it decreases the value of the specific fracture energy. The measured values for the mineral almandine are range from 2.5-3.3 J/ $\mathrm{m}^{2}$. The crushed particles are like smooth spheres. A big change of the surface during crushing induces a change in the temperature of the brittle powder, by aproximatelly $1{ }^{\circ} \mathrm{C}$.

Acknowledgements. The authors thank the Magistrate of the Statutory City of Ostrava (project 1/2005), the Ministry of Industry and Trade (project 1H-PK2/22), the Grant Agency of the Czech Republic (projects 105/06/1516, 103/07/1662), the HGF of the VŠB - Technical University of Ostrava (project IGS 2009) and the company PTV spol. s r.o., Hostivice, for their support of this research. 


\section{References}

Adamson, W. A. (1990). Physical Chemistry of Surfaces, John Wiley \& Sons, Inc., New York, USA.

Bechstedt, F. (2003). Principles of Surface Physics, Springer-Verlag, Berlin, Germany.

Brantley, S.L., Mellott, N.P. (2000). Surface Area and Porosity of Primary Silicate Minerals, American Mineralogist 85, 1767-1783.

Davidge, R.W., Tappin, G. (1968). The Effective Surface Energy of Brittle Materials, Journal of Materials Science 3, 165 173.

Friedman, M., Handin, J., Alani, G. (1972). Fracture-Surface Energy of Rocks. International Journal of Rock Mechanics and Mining Sciences 9, 757-766.

Gilman, J. J. (1960). Direct Measurement of the Surface Energies of Crystals, Journal of Applied Physics 31, $2208-2218$.

Hlavac, L.M., Hlavacova, I.M., Vasek, J. (2007). Material milling by water jets: operation of liquid jet inside cutting head, Transactions of the VŠB - Technical University of Ostrava, Mechanical series 53(1), 73-84.

Hlavac, L.M., Hlavacova, I.M., Vasek, J., Jandacka, P., Madr, V. (2009). Material grinding by water jets - feasibility and limits, Journal of Scientific Conference Proceedings 1(2), 1-7.

Hunger, M., Brouwers, H.J.H. (2009). Flow Analysis of Water Powder Mixtures, Cement \& Concrete Composites 31, 3959.

Jandacka, P., Hlavac, L.M. (2007). A Simple Method of the Determination of Shapes of Grains of Loose Materials, Proc. $8^{\text {th }}$ International Scientific Conference on Technology System Operation, September 2008, Presov.

Keller, W.D. (1954). The bonding energies of some silicate minerals, American Mineralogist 39, 783-793.

Likes, J., Machek, J. (1987). Computation of probability, SNTL, Prague, Czech Republic. (in Czech)

Lüth, H. (2001). Solid Surfaces, Interfaces and Thin Films, Springer, New York, USA.

Masteau, J.C., Thomas, G. (1999). Modeling to Understand Porosity and Specific Surface Area Changes during Tabletting, Powder Technology 101, 240-248.

Messmer, C., Bilello, J.C. (1981). The surface energy of Si, GaAs, GaP, Journal of Applied Physics 52(7), 4623-4629.

Miller, O., Freund, L.B., Needleman, A. (1999). Modeling and Simulation of dynamic fragmentation in brittle materials, International Journal of Fracture 96, 101-125.

Papelis, Ch., Um, W., Russell, Ch.E. Chapman, J.B. (2003). Measuring the Specific Surface Area of Natural and Manmade Glasses, Colloids and Surfaces A: Physicochem. Eng. Aspects 215, 221-239.

Parfitt, G.D., Sing, K.S.W. (1986). Characterization of Powder Surfaces, Academic Press, San Francisco, USA.

Pitchumani, R., Zhupanska, O., Meesters, G.M.H., Scarlett, B. (2004). Measurement and characterization of particle strength using a new robotic compression tester, Powder Technology 143-144, 56-64.

Pugno, N.M., Carpinteri, A. (2008). On Linear Elastic Fragmentation Mechanics Under Hydrostatic Compression, International Journal of Fracture 149, 113-117.

Tkacova, K. (1989). Mechanical Activation of Minerals, Elsevier, Amsterdam, Netherlands.

Tromans, D., Meech, J.A. (2002). Fracture toughness and surface energies of minerals, Minerals Engineering 15, 1027 1041.

Woensdregt, C.F. (1992). Computation of Surface Energies in an Electrostatic Point Charge Model, Physics and Chemistry of Minerals 19, 52-58. 